\title{
Deficit Convergence and Headache: The Invisible Facts
}

\section{Gaurav Dubey ${ }^{1}$, Mahesh Chandra ${ }^{2}$, Ragni Kumari ${ }^{3 *}$, Richa Jangra ${ }^{4}$ and Aysworya Mohapatra ${ }^{5}$}

${ }^{1}$ Department of Optometry, UPUMS Saifai, Etawah U.P, India.

${ }^{2}$ Department of Ophthalmology, Dr. Sushila Tewari Hospital and Govt. Medical College, Haldwani, Uttarakhand, India

${ }^{3}$ Department of Optometry, Era University, Lucknow, India

${ }^{4}$ Department of Ophthalmology, Regional Institute of Ophthalmology, PGIMS,

Rohtak, Haryana, India

${ }^{5}$ Laxmi Charitable Trust and Laxmi College of Optometry Panvel, Navi Mumbai, India

*Corresponding Author: Ragni Kumari, Department of Optometry, Era

University, Lucknow India.
Received: August 04, 2020

Published: August 25, 2020

(C) All rights are reserved by Gaurav Dubey., et al.

\section{Abstract}

The inadequate convergence is a state where your eyes will not cooperate if you look at objects in the vicinity.

This disorder allows one eye to face out with the other eye, instead of inward, causing a double or blurred vision.

Insufficiency Infusion is generally diagnosed in children and teenagers in school age. It may cause reading problems, about which parents or teachers can believe the child is experiencing learning difficulties rather than an eye disease. Persons of all ages can be treated with convergence insufficiency after a stroke or traumatic brain injury.

Keywords: Eye Strain; Headache; Convergence Insufficiency; Double Vision; Eye Fatigue

Do you have eyestrain, blurred vision, double vision, or

headache?

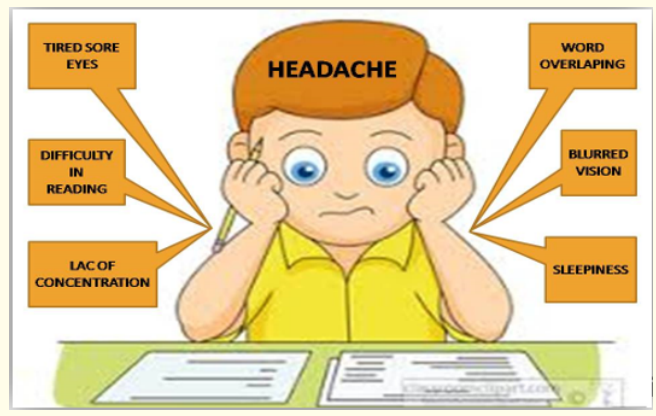

Figure 1: Related symptoms arise due to convergence insufficiency

So, if yes, you can be a sufferer of Convergence insufficiency which is a common condition characterized by a person's inability to maintain a proper binocular eye alignment on objects as they approach to near.

\section{Mechanism}

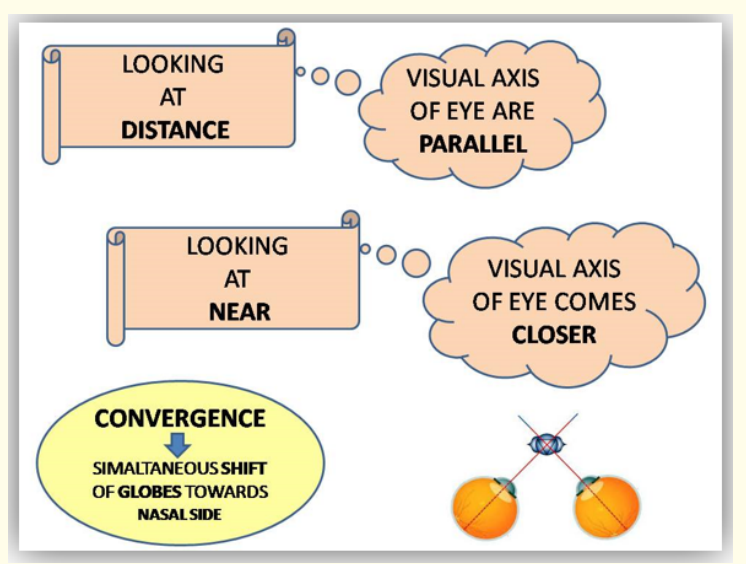

Figure 2: The position of the globes according to distance. 


\section{Convergence}

A disjugate movement in which line of sight intersects in front of eyes by rotating both eyes inward. It is a component of near response triad, with accommodation of lens and miosis of the pupil. Objectively, it can be measured either by measuring convergence response to accommodative stimuli, i.e. AC/A Ratio (accommodative convergence to accommodation) or accommodative response to convergence stimuli, i.e. CA/C Ratio (convergence accommodation to convergence). The power of convergence may deteriorate under certain circumstances that may be increased by various exercises. It is helpful to perform binocular vision at near and for stereo acuity, i.e. depth perception, binocular foveation is required.

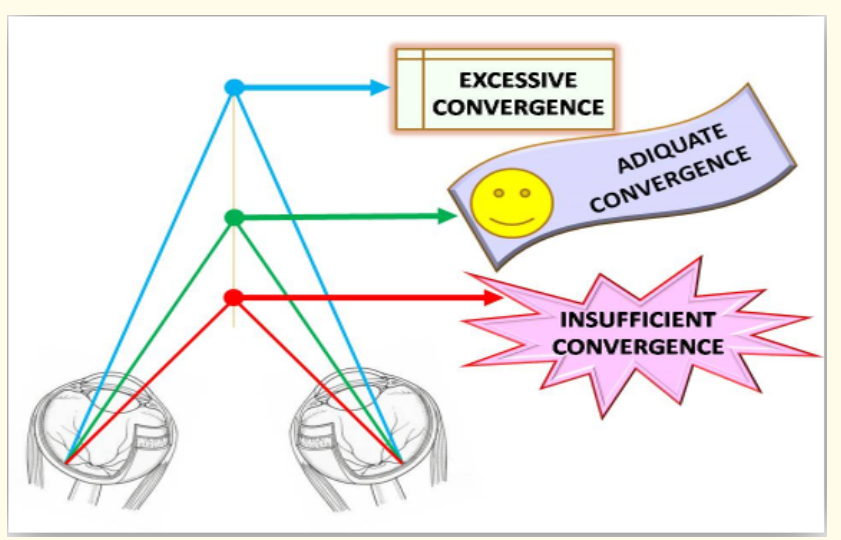

Figure 2: For trouble free work it is necessary to have efficient convergence.

Convergence insufficiency (CI): The inability to obtain or maintain adequate binocular convergence

- Typically affects individuals with higher near visual demand, i.e., students. Patients with CI usually have poor near point convergence (NPC) independent of any heterophoria. (as shown in figure 4 (a) with the patient having normal convergence and (b) with the patient having convergence insufficiency depicting poor NPC).

- Sometimes patients present with near reflex insufficiency, i.e., dual of convergence and accommodative insufficiency in which during near fixation attempted, mydriasis may be seen. Therefore, in such patients, it is important to rule out associated accommodative insufficiency before treating the patient with functional convergence insufficiency.

- Clinical features like reduced NPC, drastically reduced NPA (near point accommodation), and low or absent AC/A Ratio differentiate the case of near reflex insufficiency with convergence insufficiency.
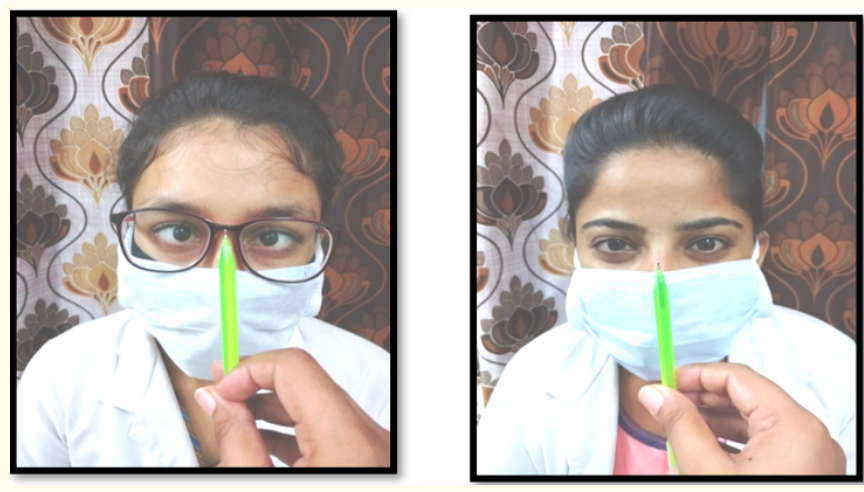

Figure 4: The patient showing convergence (a) normal NPC (b) patient having abnormal near point convergence with Exophoria showing the case of convergence insufficiency.

\section{How it happens}

The root cause is presumably innervational [1]. A drastic improvement in patient symptoms following adequate medical diagnosis, along with conclusive clinical findings of better convergence, and poor fusion convergence, appears to be correlated with near vision impairment and is often linked with significant variations from the sight impairment. Previously, Ophthalmologists believed, and Convergence insufficiency, and its signs and symptoms are considered that are related to nerve dysfunction and which, according to them, are related to the psychological problem and can be best treated by the psychiatrist [2]. It is now clear that the absence of convergence is a troublesome binocular dysfunction. The behavioral symptoms that the individual shows are essentially the product of the dissatisfaction induced by their failure to accomplish desirable near-visual activities that physicians may understand.

\section{Prevalence}

In a series of studies, the Convergence Insufficiency Care Investigator Group has recently gathered valuable data about convergence symptoms (2008 Reference, 2005 Reference) [3]. Among most of the studies, this is the oldest and leading one and scientifically has proven with the ideal symptom questionnaire. These research showed that children with inadequate convergence indicated that "fair often" or "always" while reading or working closely followed the following symptoms. Shown in figure 4.

In many studies, the investigators have reported a prevalence of convergence insufficiency of about $4.2 \%$ to $6 \%$ in school and clinic settings. The principle meaning of Convergence insufficiency includes an increase of exophoria at near, and convergence and its amplitude become low at near point [4]. 


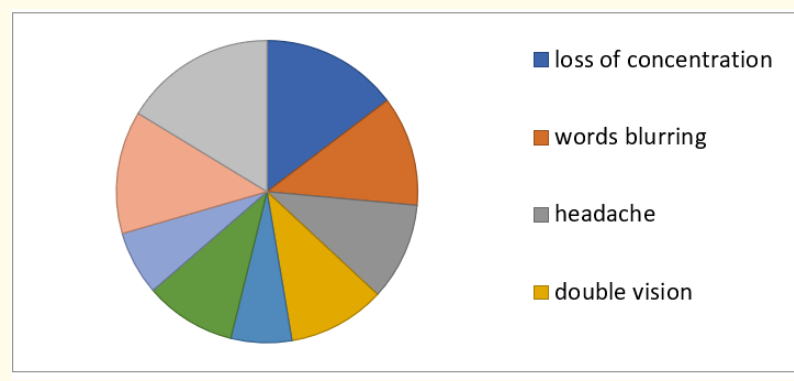

Figure 4: A pie diagram is representing the percentage of symptoms of convergence insufficiency in children.

\section{Symptoms}

Persons who have reading work, computer work, desk work, or who playing handheld video games, doing crafts, etc. generally has convergence insufficiency. They may show complain while doing such work. The affected person who has asthenopic symptoms have the most frequent complaint with their glasses and tries to change spectacles without any satisfaction.

CI patients generally present with indications/symptoms:

- Eyestrain (especially while reading or after reading).

- Headache.

- Blurred vision

- Double vision.

- Inability to concentrate

- Short attention span.

- Frequent loss of place.

- Squinting, rubbing, closing, or converging an eye.

- Sleepiness during the activity.

- Trouble remembering.

- Words appear to move, jump, swim ,or float.

- Problems with motion sickened and/or vertigo.

Causes of convergence insufficiency

- The exact etiology of $\mathrm{CI}$ is unknown. It may be associated with delayed or inadequate functional development or wide IPD (interpupillary distance).

- It may be associated with uncorrected high refractive error as hypermetropia or myopia.

- $\quad$ Long time negligence of extraocular muscular imbalances (exophoria, intermittent exotropia) may be associated with CI.

- Some of the conditions such as infection, medications, neurodegenerative diseases, myasthenia gravis or graves ophthalmopathy, trauma, or traumatic brain injury may lead to the cause of convergence insufficiency.
- Drugs like depressants, dissociative anesthetics, inhalants usually cause convergence insufficiency with HGN (horizontal gaze nystagmus).

- Cannabis usually causes $\mathrm{CI}$ even though does not cause HGN.

Do you have "convergence insufficiency?"

For this test, prepare a small rectangular card with a dark yet fine vertical line along with its breadth

Measurement of NPC:

Card test

For this test, Prepare a small, Dark, yet Fine Vertical Card along with its width for this test.

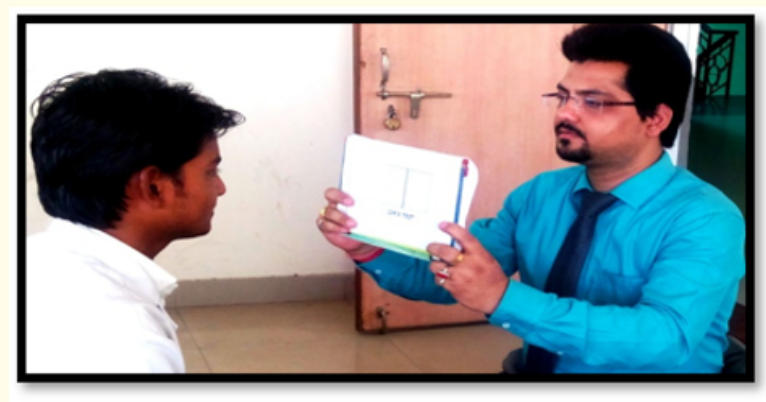

Figure 6: Card test procedure.

Procedures

How to do the test

- Hold the card in your hand, with the arm extended.

- Keep looking at the vertical line with both the eyes.

- Slowly bring the card towards your eyes.

- Does the line appear single or double?

Assessment of card test result

\begin{tabular}{|l|c|c|c|}
\hline S. N & $\begin{array}{c}\text { Patient } \\
\text { response }\end{array}$ & Card distance & Result \\
\hline 1 & Single line & $\begin{array}{c}6 \text { inches from the } \\
\text { eye }\end{array}$ & $\begin{array}{c}\text { Good Convergence } \\
\text { Power }\end{array}$ \\
\hline 2 & $\begin{array}{c}\text { Double } \\
\text { Line. }\end{array}$ & $\begin{array}{c}\text { Inner limit (With- } \\
\text { in) of 6 inches }\end{array}$ & $\begin{array}{c}\text { Both eyes not pointing } \\
\text { towards the line }\end{array}$ \\
\hline
\end{tabular}

Table 1

*Line starts appearing double means greater insufficiency and Greater distance of card from the eyes.

RAF rule

- The RAF rule is a near-point convergence (NPC) measurement scale and a close-point accommodation (NPA), in which the near-point convergence range is noted by age in the centersection. 
- Convergence insufficiency is said to exist if NPC is more than 6-7 centimeters from baseline.

- NPA is normal and corresponds to the age of the patient.

(However, NPA is important to measure in each case for differential diagnosis in a patient with convergence insufficiency with near reflex insufficiency).

\section{Measurement of vergence}

Prism

Positive fusional vergence (convergence) is generally is low but negative fusional vergence (divergence) is normal.

\section{Synaptophore}

$\mathrm{CI}$ is said to exist if there is difficulty in attaining 30-degree adduction. Positive fusional vergence, less than $15-20$, is usually due to convergence insufficiency.

\begin{tabular}{|c|}
\hline $\begin{array}{c}\text { Visual assessment } \\
\text { Retinoscopy }\end{array}$ \\
\hline Cover test \\
\hline $\begin{array}{c}\text { Ocular Movement } \\
\text { Examination }\end{array}$ \\
\hline $\begin{array}{c}\text { Positive and Negative } \\
\text { Reserve of the patient }\end{array}$ \\
\hline $\begin{array}{c}\text { Near point convergence and } \\
\text { near point accommodation }\end{array}$ \\
\hline $\begin{array}{c}\text { MEM retinoscopy } \\
\text { (monocular -estimation method) }\end{array}$ \\
\hline E.g., Performed at 40 cm to check accommodation \\
associated convergence insufficiency.
\end{tabular}

Figure a: A general stepwise procedure to investigate a case of convergence insufficiency.

\section{Recommendations for the exercises}

- Before we go for the eye exercise for farsightedness, there are few points to be kept in mind:

- The steps of procedure should be clarified.

- The use of glass or contact lenses should be avoided unless you are not instructed.
- Vision charts or targets should always be aligned in non-glaring light.

- $\quad$ During the time of exercise, strain on the eyes should be avoided. If it persists eye should be closed for relaxation so gently for a short time.

- Early morning time is considered for the best time for the exercise of the eye because the rest of the day strain develops due to working. During exercise, the Pre- and Post- session of exercise should be followed by rest for relaxing the eye muscle.

\section{Treatment}

Excellent prognosis has attained in most cases of convergence insufficiency. Treatment of CI includes optical treatment, orthoptic treatment, and prism therapy.

\section{Optical Treatment}

Correct glasses should be prescribed by doing proper refraction for any associated refractive errors. Convergence can be stimulated by stimulating accommodation doing the below measures:

- Hypermetropic patients should do under-correction in the prescription.

- Myopic patients should give full correction.

Orthoptic therapy

- Widely used for the following purposes: To increase fusional convergence amplitudes.

- To enhance voluntary convergence (primary treatment of convergence insufficiency).

Most eye care providers use certain types of home treatments and counseling to treat children diagnosed with CI; another study suggests that office counseling by a well trained therapist along with home, strengthening is safer.

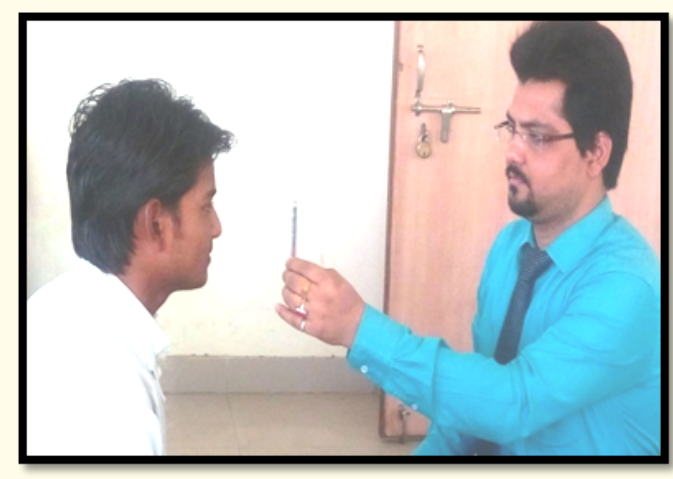

Figure 7: Method of exercise. 


\section{Prism therapy}

Prisms can be prescribed in such patients with base-in (BI) with best-corrected visual acuity (BCVA) adding plus lenses for near to improve fusional reserve.

\section{Suggested eye exercises for convergence insufficiency}

- Pen Push-up Exercise: It is a widely accepted home-based orthoptic exercise in which the focus point of the patient should be at the nib of the pen/pencil/sketch pen (any pointing object).

- String Exercise: This exercise is applied to achieve correct fixation and simultaneous perception on the same time to overcome suppression.

\section{- The ' $X$ ' card Exercise:}

- This exercise is also considered an effective method for the convergence exercise, and it allows viewing through both the eyes together.

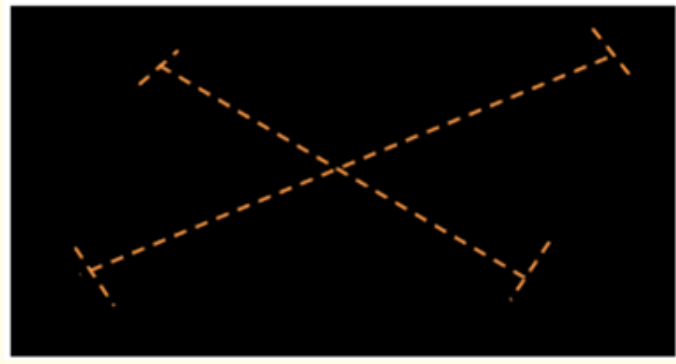

Figure 8: X-Card.

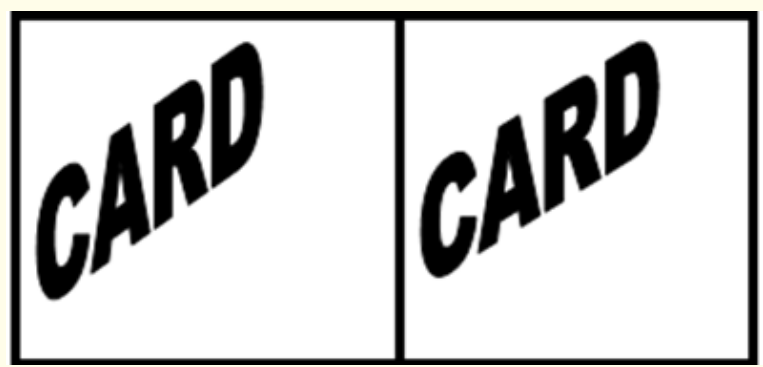

Figure 9: Fusion Card.

\section{Fusion exercise}

These exercises will strengthen our extraocular muscles hence improve their ability to fuse two images. Many newer technologies nowadays present in daily life to get rid of the problem of convergence insufficiency.

Hospital-based, many instruments have been designed like Synaptophore, RAF rule, Vectogram, Brock string help to improve convergence in meanwhile by enhancing the fusional vergence of the patient. Among them, vectogram also works on stereoacuity as well as fusional vergence.

\section{Physiologic diplopia exercises}

Diplopia is created by Stereogram cards at arm's length held in front of the patient with a pencil placed in between patient and card resulting in uncrossed diplopia noticed by the patient. This exercise can be advised to the patient to do at home.

\section{Computer-based exercises}

A computer-based orthoptic program is gradually increasing the power of convergence; requires clearing the image on the computer screen.

\section{Acknowledgment}

The authors would like to thanks the Department of Optometry, Faculty of Paramedical Sciences, Saifai, Etawah for providing all possible support for the smooth conduction of this short communication article. The author would also like to extend warm regards to the Students Akash Kumar (UPUMS), Neha and Sonika from (PGIMS Rohtak) for their Voluntary participation.

\section{Funding}

No funding sources.

\section{Conflict of Interest}

Authors agree that there is no source of conflict of interest.

\section{Bibliography}

1. Von Noorden GK. "Theory and Management of Strabismus Binocular Vision and Ocular Motility". $5^{\text {th }}$ edition. Mosby-Year book (1995): 468-476.

2. Brown B. "The convergence insufficiency masquerade". American Orthoptic Journal 40 (1990): 94-97. 
3. http://www.convergenceinsufficiency.net/detail.asp?id=20

4. Convergence Insufficiency Treatment Trial (CITT) Study Group. "The convergence insufficiency treatment trial: design, methods, and baseline data". Ophthalmic Epidemiology 15.1

(2008): 2436.

\section{Assets from publication with us}

- Prompt Acknowledgement after receiving the article

- Thorough Double blinded peer review

- Rapid Publication

- Issue of Publication Certificate

- High visibility of your Published work

Website: www.actascientific.com/

Submit Article: www.actascientific.com/submission.php

Email us: editor@actascientific.com

Contact us: +919182824667 